\title{
Diagnostic discrepancy between bronchoalveolar lavage and transbronchial biopsy from bronchoscopies of HIV patients with pneumonia: toward an integral diagnosis
}

This article was published in the following Dove Press journal:

HIVIAIDS - Research and Palliative Care

\author{
Olivia Sánchez-Cabral' \\ Dina Martínez-Mendoza ${ }^{1,2}$ \\ Ángel Paul Flores-Bello 3 \\ José Arturo Martínez- \\ Orozco 4 \\ Rosa María Rivera-Rosales ${ }^{5}$ \\ César Luna-Rivero 5 \\ Patricio Santillán-Doherty ${ }^{6}$ \\ Gustavo Reyes-Terán ${ }^{7}$ \\ 'Interventional Pulmonology Unit, \\ ${ }^{2}$ Hospital Epidemiology Surveillance \\ Unit, ${ }^{3}$ Clinic of Tuberculosis and \\ Pleural Diseases, ${ }^{4}$ Department of \\ Infectious Diseases and Clinical \\ Microbiology, ${ }^{5}$ Anatomic Pathology \\ Service, ${ }^{6}$ Medical Direction, \\ ${ }^{7}$ Department of Research in Infectious \\ Diseases, National Institute of \\ Respiratory Diseases Ismael Cosío \\ Villegas, Mexico City, Mexico
}

Correspondence: Dina MartínezMendoza

Hospital Epidemiology Surveillance Unit, National Institute of Respiratory Diseases Ismael Cosío Villegas, Calzada de Tlalpan 4502, Col Sección XVI, Mexico City 14080, Mexico

Email dinamarty@gmail.com
Background: The key diagnostic method for the evaluation of lung diseases associated with HIV infection is bronchoscopy, with bronchoalveolar lavage (BAL) being the most commonly used sampling technique. Transbronchial biopsy (TBB) is often complementary.

Setting: This is a retrospective cross-sectional study to determine the diagnostic usefulness of bronchoscopy with simultaneous samples obtained through BAL and TBB in HIV-infected patients with pneumonia at the National Institute of Respiratory Diseases Ismael Cosío Villegas. Methods: In this cross-sectional study (January 2014-December 2015), the diagnostic yield of bronchoscopic samples from all HIV-positive patients with pneumonia aged $>18$ years, from procedures performed in the Interventional Pulmonology Unit, was analyzed and recorded in its database. The diagnostic yield concordance between BAL and TBB samples was evaluated by kappa index calculation.

Results: A total of 198 procedures on 189 HIV-infected patients with pneumonia were performed. A total of $167 / 189$ (88.4\%) patients were male, and the mean age was 34.7 years (SD \pm 9.0 ). Overall, the diagnostic yield for either technique was $87.9 \%$ (174/198), but it was higher for TBB, its yield being $78.8 \%$ (156/198). In contrast, that of BAL was $62.1 \%(123 / 198)(P=0.001)$. The overall diagnostic yield concordance between TBB and BAL was insignificant $(\kappa=0.213$, $P<0.001)$. It improved for fungal infections, pneumocystosis, and tuberculosis $(\kappa=0.417,0.583$, and 0.462 , respectively, all $P<0.001$ ).

Conclusion: Our results show that the simultaneous obtainment of BAL and TBB samples is useful and complementary in the diagnosis of infections and malignancies in HIV-infected patients. Additionally, they are safe procedures in this group of patients.

Keywords: bronchoalveolar lavage, transbronchial biopsy, HIV, BAL, TBB, interventional bronchoscopy, bronchoscopy

\section{Background}

Respiratory diseases are frequent in HIV-infected patients and are a leading cause of morbidity and mortality despite combined antiretroviral therapy (ART). The spectrum of pulmonary manifestations is wide and includes infectious and noninfectious diseases, which frequently have overlapping clinical and radiological manifestations. Additionally, coinfections are frequent and their isolation with conventional methods is difficult. The most frequent infections are bacterial pneumonia, tuberculosis, Pneumocystis jirovecii pneumonia (PJP), and fungal infections (coccidioidomycosis, histoplasmosis, and cryptococcosis). ${ }^{1-6}$ The key diagnostic method for the evaluation of lung diseases 
associated with HIV is bronchoscopy, with bronchoalveolar lavage (BAL) being the most commonly used sampling technique, while transbronchial biopsy (TBB) is often complementary. Both are useful and safe procedures. ${ }^{2,7}$ However, the utility of each of these techniques in infectious diseases is different, especially for PJP and cytomegalovirus (CMV) infection, and TBB is more useful for bacterial infections and noninfectious disease such as malignancies. ${ }^{2,8}$ Our objective was to determine the diagnostic usefulness of bronchoscopy with simultaneous sampling obtained with BAL and TBB in HIV-infected patients with pneumonia.

\section{Methods}

This is a retrospective cross-sectional study, which was approved by the Research and Ethics Committees of the National Institute of Respiratory Diseases Ismael Cosío Villegas of Mexico, with code number C72-16. Informed consent waiver from the Institutional Research and Ethics Committees was requested, since this was a retrospective study, and the confidentiality of the patients included in the study was strictly protected. A total of 189 patients older than 18 years diagnosed with HIV and registered in the database of the Interventional Pulmonology Unit of our institution were subjected to a diagnostic bronchoscopy, which included BAL and TBB. The patients were admitted to the External Consultation Service, the Emergency Department and Clinical Services of the INER, or were referred by medical interconsultation from other institutions because they presented with pneumonia diagnosed either clinically or by chest tomography, with indication to perform diagnostic bronchoscopy by means of BAL and TBB study during the period from January 2014 to December 2015. The population size was 198 procedures, considering 1) the finite population correction factor $(N)$, an estimated 400 outpatients or hospitalized patients with HIV and pneumonia treated within 2 years at the institute; 2) an overall diagnostic yield of $50 \%( \pm 5)$, according to the published variability of the diagnostic yields of the different pulmonary samples; 3 ) 95\% CIs; and 4) the formula: $N=(\mathrm{EDFF} \times N p[1-p]) /(d 2 /$ $Z 21-\alpha / 2 \times[N-1]+p \times[1-p])$, which was obtained through the OpenEpi software, Version 3.

BAL and TBB samples were cultured as follows. In fungal infection, the samples were cultured on sabouraud and sabouraud with antibiotics culture media and the species were identified under the cotton blue microscopy. For the diagnosis of $P$. jirovecii, direct immunofluorescence microscopy, as the gold standard, was performed. Special staining with grocott, calcofluor white, and Wright stains for fungal identification was also performed. In mycobacteria, the samples were cultured on liquid (BACTEC MGIT 960) and solid (Löwenstein-Jensen) media and the species were identified using the line probe assay (HAIN) tests. For drug susceptibility testing in Mycobacterium tuberculosis, BACTEC MGIT 960 SIRE kit was used. GeneXpert ${ }^{\circledR}$ MTB/RIF for M. tuberculosis diagnosis was also performed in all samples. In bacteria, the samples were cultured on liquid and solid agar media and automated VITEK 2 was used for identification and drug susceptibility testing. In viral infection, multiplex real-time polymerase chain reaction (PCR) LUMINEX assay for respiratory viral diagnosis and Anyplex ${ }^{\mathrm{TM}}$ II multiplex real-time PCR RPB5 for respiratory bacteria platforms were performed. In CMV, tissue real-time PCR and histopathological analysis were performed.

Samples for histopathological analysis obtained transbronchially (TBB) were kept in formaldehyde buffer, $\mathrm{pH} 7.1$ (EMD Millipore, Billerica, MA, USA), and BAL samples were kept in 10 cc carbowax (polyethyleneglycol 4000; Merck Millipore, Billerica, MA, USA).

All procedures were performed and supervised by an expert interventional pulmonologist.

BAL is performed using the pulmonary bronchoscopic wedging technique in the most affected lung subsegment with $180 \mathrm{~mL}$ saline instillation, recovering at least $45 \%$ of instillate. The material collected in vial-like containers is sent to the Microbiology and Anatomic Pathology Department.

In TBB, lung biopsy is performed using the bronchoscopic wedging technique at the most affected site under fluoroscopic guidance and is sent to the Microbiology and Anatomic Pathology Department.

Helical computed tomography of the chest with contrast was performed, with reconstruction in window for the lung and mediastinum, with a section thickness of $3 \mathrm{~mm}$ with SIEMENS SOMATOM tomograph definition 128. Prior to tomography, the site with the greatest damage is identified, and TBB and BAL are performed.

Variables were evaluated according to their distribution. The diagnostic yield of the samples obtained by bronchoscopy (BAL and TBB) was analyzed with chi-square and Fisher's exact tests for categorical variables, and $t$-test was used for continuous independent variables. The kappa index was used to evaluate the diagnostic yield concordance between the samples obtained with BAL and TBB. Results were significant at a $P$-value of $<0.05$. The statistical analysis was performed using the IBM SPSS Statistics 21 software.

\section{Results}

A total of 198 procedures on $189 \mathrm{HIV}$-infected patients with pneumonia were performed. A total of 167/189 (88.4\%) 
patients were male, with a mean age of 34.7 years (SD 土9.0) (Table 1). Information about previous ART or antibiotic therapy prior to bronchoscopy was available from 167 patients $(84.3 \%)$. A total of $92.8 \%(155 / 167)$ of patients had taken antibiotics for a mean of 5.4 days ( $\mathrm{SD} \pm 5.8$ ), and $36.6 \%(60 / 164)$ of patients were on ART prior to evaluation, with a mean ART duration of 7.3 months (SD \pm 22.6 ) prior to bronchoscopy.

\section{Overall diagnostic yield}

Overall diagnostic yield for either technique was $87.9 \%$ (174/198), but it was higher for TBB, the yield of this method being $78.8 \%(156 / 198)$ in contrast to $62.1 \%(123 / 198)$ for BAL $(P=0.001)$. The most frequent diagnosis was infections, with etiologic agent identification in $79.3 \%(157 / 198)$ (Tables 1 and 2).

Table I Summary of procedures performed on I89 HIV-infected patients with pneumonia subjected to 198 bronchoscopies

\begin{tabular}{|c|c|c|}
\hline Patients' characteristics & $\mathbf{n}$ & $\%$ \\
\hline Males & 167 & 88.4 \\
\hline Mean age \pm SD & 34.7 & 9.0 \\
\hline \multicolumn{3}{|l|}{ Type of samples and processing } \\
\hline BAL samples & 198 & 100.0 \\
\hline $\begin{array}{l}\text { BAL samples processed in Pathological } \\
\text { Anatomy }\end{array}$ & 191 & 96.5 \\
\hline $\begin{array}{l}\text { BAL samples subjected to microbiological } \\
\text { processing }\end{array}$ & 198 & 100.0 \\
\hline TBB samples & 198 & 100.0 \\
\hline $\begin{array}{l}\text { TBB samples processed in Pathological } \\
\text { Anatomy }\end{array}$ & 193 & 97.5 \\
\hline $\begin{array}{l}\text { TBB samples subjected to microbiological } \\
\text { processing }\end{array}$ & 192 & 97.0 \\
\hline \multicolumn{3}{|l|}{ Absolute $\mathrm{CD} 4^{+}$cell counts } \\
\hline$<50 / \mathrm{mm}^{3}$ & 106 & 57.0 \\
\hline $50-99 / \mathrm{mm}^{3}$ & 32 & 17.2 \\
\hline $100-199 / \mathrm{mm}^{3}$ & 21 & 11.3 \\
\hline $200-499 / \mathrm{mm}^{3}$ & 19 & 10.2 \\
\hline$\geq 500 / \mathrm{mm}^{3}$ & 8 & 4.3 \\
\hline $\begin{array}{l}\text { Population with known history of antibiotic use } \\
\text { prior to bronchoscopy }\end{array}$ & $155 / 167$ & 92.8 \\
\hline $\begin{array}{l}\text { Population with known history of antiretroviral } \\
\text { treatment took prior to bronchoscopy }\end{array}$ & $60 / 164$ & 36.6 \\
\hline \multicolumn{3}{|l|}{ Global diagnosis } \\
\hline Infectious agent & $157 / 198$ & 79.3 \\
\hline With a single etiologic agent ${ }^{\mathrm{a}}$ & $102 / 157$ & 64.9 \\
\hline With more than a single agent (coinfections) & $55 / 157$ & 35.0 \\
\hline Noninfectious, benign & $14 / 198$ & 7.0 \\
\hline Malignancy & $3 / 198$ & 3.0 \\
\hline Mixed (malignancy with etiologic agent) & $3 / 198$ & 3.0 \\
\hline Global diagnostic yield of bronchoscopy & $174 / 198$ & 87.9 \\
\hline Without diagnosis from bronchoscopy & $24 / 198$ & 12.1 \\
\hline
\end{tabular}

Note: ${ }^{\mathrm{a} T B B}$.

Abbreviations: BAL, bronchoalveolar lavage; TBB, transbronchial biopsy.

\section{BAL and TBB yields according to specific diagnosis}

Of all samples, 247 samples were useful for diagnosis, 173 (70\%) samples were obtained with TBB, and $161(65.2 \%)$ samples were obtained with BAL; $92.3 \%$ (228) led to the identification of an infectious cause, while $13(5.3 \%)$ corresponded to benign neoplasia and 6 (2.4\%) corresponded to malignant neoplasia. The most frequent infection was fungal infection in $57.5 \%$ (131/228), followed by bacterial infection in $18.9 \%(43 / 228)$, mycobacterial infection in $16.2 \%$ (37/228), and viral infection in 7.5\% (17/228). P. jirovecii was the most frequently identified pathogen in $91.6 \%$ (107), followed by M. tuberculosis complex in 93.8\% (32) (Table 2).

BAL was a better tool for the identification of mycobacteria $(94.6 \%$ vs $32.4 \%, P<0.001)$ and viruses $(70.6 \%$ vs $35.3 \%$, $P=0.001$ ) except CMV. Regarding the latter, TBB identified all cases of CMV infection, with only $1 / 6$ being isolated through BAL. As for fungal infection, TBB performed better than BAL $(87.0 \%$ vs $67.2 \%, P<0.001)$. With respect to bacteria, there was no difference between both techniques, except Escherichia coli (Gram-negative Enterobacteriaceae) for which TBB was superior $(82.4 \%$ vs $52.9 \%, P<0.001)$ (Table 3 ). TBB was the only method that led to the diagnosis of neoplasia either benign or malignant (Table 4).

The overall concordance between TBB and BAL was nonsignifcant $(\kappa=0.213, P<0.001)$; however, it improved for the following diagnostic categories: fungal infections ( $\kappa=0.417, P<0.001), \operatorname{PJP}(\kappa=0.583, P<0.001)$, and tuberculosis $(\kappa=0.462, P<0.001)$ (Table 5).

\section{Coinfections}

Positive isolates were obtained from 79.3\% (157) procedures, and $35.0 \%$ (55) of them occurred as coinfections. The agents more frequently isolated from coinfections were $P$. jirovecii in 44/55 (80.0\%) and M. tuberculosis complex in 19/54 (34.5\%). In contrast, of all patients who had $P$. jirovecii, $41.1 \%(44 / 107)$ had a coinfection, and of all patients who had M. tuberculosis complex, 59.4\% (19/32) had also coinfection. The following data were found to be nonsignificant regarding the development of infections with one or more organisms (coinfections) or the type of infectious agent: previous antibiotic treatment, length of treatment, and previous ART.

PJP

Regarding PJP, BAL had a sensitivity of $71.9 \%$, with a negative predictive value (NPV) of $75.2 \%$ and a diagnostic precision of $84.9 \%$, while TBB for PJP diagnosis had a 
Table 2 Diagnostic yield according to the type of sample in HIV-infected patients with pneumonia

\begin{tabular}{|c|c|c|c|c|c|c|c|}
\hline \multirow[t]{2}{*}{ Type of sample according to diagnosis } & \multicolumn{2}{|l|}{ TBB } & \multicolumn{2}{|c|}{ BAL } & \multicolumn{2}{|c|}{ Total } & \multirow[t]{2}{*}{$P *$} \\
\hline & $\mathbf{n}$ & $\%$ & $\mathbf{n}$ & $\%$ & $\mathbf{n}$ & $\%$ & \\
\hline Etiologic agent & 154 & 67.5 & 161 & 70.6 & 228 & & \\
\hline Fungal & 114 & 87.0 & 88 & 67.2 & $|3|$ & & $<0.001$ \\
\hline Mycobacteria & 12 & 32.4 & 35 & 94.6 & 37 & & $<0.001$ \\
\hline Bacteria & 22 & 51.2 & 26 & 60.5 & 43 & & 0.189 \\
\hline Viruses & 6 & 35.3 & 12 & 70.6 & 17 & & 0.001 \\
\hline Benign diagnosis (other than infections) & 13 & 100.0 & 0 & 0.0 & 13 & 5.3 & \\
\hline Malignancies & 6 & 100.0 & 0 & 0.0 & 6 & 2.4 & \\
\hline \multicolumn{8}{|l|}{ Diagnostic yield according to origin } \\
\hline Diagnostic yield of bronchoscopies & 156 & 78.8 & 123 & 62.1 & 174 & 87.9 & 0.001 \\
\hline Total number of diagnoses reached from samples & 173 & 70.0 & 161 & 65.2 & 247 & 100 & 0.001 \\
\hline
\end{tabular}

Note: *P-value for $\chi^{2}$.

Abbreviations: BAL, bronchoalveolar lavage; TBB, transbronchial biopsy.

Table 3 Infectious etiologic agent identified in 157 procedures performed on HIV-infected patients with pneumonia according to the sample obtained

\begin{tabular}{|c|c|c|c|c|c|c|c|}
\hline \multirow[t]{2}{*}{ Diagnosis } & \multicolumn{2}{|c|}{ TBB } & \multicolumn{2}{|c|}{ BAL } & \multirow[t]{2}{*}{ Total } & \multirow[t]{2}{*}{$\%$} & \multirow[t]{2}{*}{$P *$} \\
\hline & $\mathbf{n}$ & $\%$ & $\mathbf{n}$ & $\%$ & & & \\
\hline \multicolumn{8}{|l|}{ Fungal } \\
\hline Pneumocystis jirovecii & 98 & 91.6 & 76 & 71.0 & 107 & 57.5 & $<0.001$ \\
\hline Dimorphic fungi & 10 & 58.8 & II & 64.7 & 17 & & $<0.001$ \\
\hline Yeasts & 5 & 83.3 & I & 16.7 & 6 & & \\
\hline Molds & 3 & 100.0 & 0 & 0.0 & 3 & & \\
\hline Subtotal & 116 & 88.5 & 88 & 67.2 & $13 \mid$ & & 0.001 \\
\hline \multicolumn{8}{|l|}{ Mycobacteria } \\
\hline Mycobacterium tuberculosis & 12 & 37.5 & 30 & 93.8 & 32 & 16.2 & $<0.001$ \\
\hline MAC & 2 & 40.0 & 4 & 80.0 & 5 & & 0.080 \\
\hline Subtotal & 14 & 37.8 & 34 & 91.9 & 37 & & $<0.001$ \\
\hline \multicolumn{8}{|l|}{ Bacteria } \\
\hline Gram-negative Enterobacteriaceae & 14 & 82.4 & 9 & 52.9 & 18 & 18.9 & $<0.001$ \\
\hline Gram-negative non-Enterobacteriaceae & 2 & 14.3 & 12 & 85.7 & 14 & & \\
\hline Gram-positive rods & 0 & 0.0 & 1 & 100.0 & 1 & & \\
\hline Gram-positive cocci & 5 & 62.5 & 3 & 37.5 & 8 & & \\
\hline Atypical bacteria & 0 & 0.0 & 1 & 100.0 & 1 & & \\
\hline Subtotal & 21 & 48.8 & 26 & 60.5 & 43 & & $<0.001$ \\
\hline \multicolumn{8}{|l|}{ Viruses } \\
\hline Respiratory viruses & 0 & 0.0 & II & 100.0 & 11 & 7.5 & \\
\hline Cytomegalovirus & 6 & 100.0 & I & 16.7 & 6 & & \\
\hline Subtotal & 6 & 35.3 & 12 & 70.6 & 17 & & \\
\hline Total & 154 & 67.5 & 161 & 70.6 & 228 & 100.0 & \\
\hline
\end{tabular}

Note: *P-value for $\chi^{2}$.

Abbreviations: BAL, bronchoalveolar lavage; MAC, Mycobacterium avium complex; TBB, transbronchial biopsy.

sensitivity of $89.7 \%$, an NPV of $89.2 \%$, and a diagnostic precision of $94.4 \%$.

\section{Tuberculosis}

The prevalence of tuberculosis in our population was $16.2 \%$ (32/198). Diagnosis was performed through samples obtained by culture in BAL in $93.8 \%(30 / 32)$, by GeneXpert in BAL in $53.1 \%(17 / 32)$, and by culture in $\mathrm{TBB}$ in $37.5 \%$
$(12 / 32)$. TBBs added the $6.3 \%$ (2) to the overall prevalence that would have not been obtained by BAL. The sensitivity of GeneXpert in BAL compared with culture in BAL, as the gold standard, was $56.7 \%(39.2-72.6)$, with a specificity of $100 \%$ (96.5-100), a positive predictive value of $100 \%$ (81.6-100), an NPV of 89.2\% (82.3-93.6), a diagnostic precision of $90.5 \%$ (84.4-94.4), and Cohen's kappa concordance $0.67(0.5132-0.8295, P<0.001)$. When the sum 
of tuberculosis diagnoses by culture and GeneXpert ${ }^{\circledR}$ by BAL and TBB culture was used as gold standard, sensitivity was $53.1 \%$ (35-70.5), with a specificity of $100 \%$ (97-99.9), a positive predictive value of 100\% (77.1-99.5), an NPV of $91.2 \%$ (85.7-94.8), and a diagnostic precision of $92.0 \%$ (85.7-94.8) (Table 5).

\section{Yield of BAL and TBB according to tomographic imaging}

We could retrieve tomographic studies from 155 (78.3\%) patients. A better correlation was observed for TBB than for BAL in ground glass opacities ( $84.3 \%$ vs $66.1 \%, P=0.008)$, consolidation ( $88.3 \%$ vs $63.6 \%, P=0.04)$ or cysts $(90.9 \%$ vs $68.2 \%, P=0.03)$. These differences were significant.

\section{Complications}

Safety was a crucial concern for the implementation of the BAL and TBB procedures. Complications occurred in $8.1 \%$ $(16 / 198)$ of patients; in total, they accounted for 22 events. All cases were fully resolved, and no perioperative deaths occurred. The complications and their management for each

Table 4 Noninfectious diagnoses according to sample type in HIV-infected patients with pneumonia

\begin{tabular}{|c|c|c|c|c|c|}
\hline \multirow[t]{2}{*}{ Noninfectious diagnoses } & \multicolumn{2}{|c|}{ TBB } & \multicolumn{2}{|c|}{ BAL } & \multirow[t]{2}{*}{ Total } \\
\hline & $\mathbf{n}$ & $\%$ & $\mathbf{n}$ & $\%$ & \\
\hline \multicolumn{6}{|l|}{ Noninfectious benign diagnoses } \\
\hline $\begin{array}{l}\text { Histopathological pneumonia } \\
\text { diagnosis, not culture proven }\end{array}$ & 6 & 100.0 & 0 & 0.0 & 6 \\
\hline Granulomatous disease & 5 & 100.0 & I & 20.0 & 5 \\
\hline Alveolar hemorrhage & 3 & 100.0 & 0 & 0.0 & 3 \\
\hline Total & 14 & 100.0 & I & 0.0 & 14 \\
\hline \multicolumn{6}{|l|}{ Malignancies } \\
\hline Kaposi's sarcoma & 3 & 100.0 & 0 & 0.0 & 3 \\
\hline B-cell lymphoma & 2 & 100.0 & 0 & 0.0 & 2 \\
\hline Adenocarcinoma & 1 & 100.0 & 0 & 0.0 & 1 \\
\hline Total & 6 & 100.0 & 0 & 0.0 & 6 \\
\hline
\end{tabular}

one were as follows: pneumothorax with chest tube placement $(4.5 \%)$; desaturation with supplemental oxygen $(3 \%)$; bronchospasm with bronchodilator nebulization $(0.5 \%)$; moderate bleeding (2.5\%), which was controlled with cold saline solution instillation, argon plasma cauterization balloon occlusion, and/or saline solution plus adrenaline instillation. Finally, patients who required intubation were $0.5 \%$ (Table 6 ).

\section{Discussion}

Globally, microorganism isolation with all methods used was $87.9 \%$, with TBB being superior to BAL ( $78.8 \%$ vs $62.1 \%$, $P=0.001$ ); these results are comparable to those from Cazzadori et al. ${ }^{9}$ In their study, 79 HIV-infected patients with lung infiltrates were subjected to 84 bronchoscopies with a positive yield of $79.7 \%$, being higher for TBB than for BAL (77.3\% vs $47.6 \%, P<0.001$ ), and TBB increased the diagnostic yield of BAL in $32.1 \%$. Salzman et a ${ }^{10}$ also reported an additional $26 \%$ yield when TBB was obtained in 205 bronchoscopies performed in $182 \mathrm{HIV-infected} \mathrm{patients.} \mathrm{In} \mathrm{general,} \mathrm{both}$ methods are useful in these patients. Regarding PJP, BAL can detect this infection in up to $90 \%$ of cases. ${ }^{11}$ This figure can reach $100 \%$ when it is combined with TBB. ${ }^{12}$

In our population, $57 \%$ had CD4 counts $<50$ cells $/ \mathrm{mL}$ and $85.5 \%$ had CD4 counts $<200$ cells $/ \mathrm{mL}$; at CD4 levels $>400$ cells $/ \mathrm{mL}$, patients are at risk of infection by relatively virulent organisms, such as bacteria and tuberculosis (TB). Lung cancer can also occur at this stage. This explains coinfections in HIV-infected patients, where etiologic agents were isolated in $79.3 \%$ of procedures and $34.4 \%$ had an additional coinfection, with P. jirovecii being the most frequent followed by $M$. tuberculosis complex. The most frequent coinfection was $P$. jirovecii with $M$. tuberculosis complex followed by P. jirovecii with Histoplasma capsulatum. With CD4 cell counts between 200 and 400 cells $/ \mathrm{mL}$, patients may experience recurrent infection, as well as lymphoma. Opportunistic infections and Kaposi's sarcoma are rare at CD4 levels

Table 5 Kappa concordance index between TBB and BAL according to specific diagnoses in HIV-infected patients with pneumonia

\begin{tabular}{|c|c|c|c|c|c|c|c|c|}
\hline \multirow[t]{2}{*}{ Diagnosis } & \multicolumn{2}{|c|}{ TBB } & \multicolumn{2}{|c|}{ BAL } & \multicolumn{2}{|c|}{ Total } & \multirow{2}{*}{$\begin{array}{l}\text { Kappa } \\
\text { index }\end{array}$} & \multirow[t]{2}{*}{$P *$} \\
\hline & $\bar{n}$ & $\%$ & n & $\%$ & $\bar{n}$ & $\%$ & & \\
\hline Bacterial infections & 20 & 10.1 & 25 & 12.6 & 41 & 20.7 & 0.074 & 0.295 \\
\hline Viral infections & 6 & 3.0 & 9 & 4.5 & 13 & 6.6 & 0.239 & 0.001 \\
\hline Fungal infections & 102 & 51.5 & 84 & 42.4 & 122 & 61.6 & 0.417 & $<0.001$ \\
\hline Malignancies & 6 & 3.0 & 0 & 0.0 & 6 & 3.0 & 0 & \\
\hline Total & 156 & 78.8 & 123 & 62.1 & 174 & 87.9 & 0.213 & 0.001 \\
\hline Pneumocystis jirovecii & 96 & 48.5 & 77 & 38.9 & 107 & 54.0 & 0.583 & $<0.001$ \\
\hline Mycobacterium tuberculosis & 13 & 6.6 & 30 & 15.2 & 32 & 16.2 & 0.462 & $<0.001$ \\
\hline
\end{tabular}

Note: *P-value for $\chi^{2}$.

Abbreviations: BAL, bronchoalveolar lavage; TBB, transbronchial biopsy. 
Table 6 Complications after transbronchial biopsy and bronchoalveolar lavage in HIV-infected patients with pneumonia

\begin{tabular}{|c|c|c|c|c|c|c|}
\hline Patient & $\begin{array}{l}\text { Pneumothorax, } \\
\text { n (\%) }\end{array}$ & $\begin{array}{l}\text { Desaturation, } \\
\text { n (\%) } \\
\end{array}$ & $\begin{array}{l}\text { Moderate bleeding, } \\
\text { n (\%) }\end{array}$ & $\begin{array}{l}\text { Bronchospasm, } \\
\text { n (\%) }\end{array}$ & $\begin{array}{l}\text { Intubation, } \\
\text { n (\%) } \\
\end{array}$ & Diagnosis \\
\hline & $9(4.5 \%)$ & $6(3.0 \%)$ & $5(2.5 \%)$ & I (0.5\%) & $I(0.5 \%)$ & \\
\hline 1 & 0 & 0 & 1 & 0 & 0 & Pseudomonas aeruginosa \\
\hline 2 & 0 & 0 & 0 & I & 0 & $\begin{array}{l}\text { Pneumocystis jirovecii and } \\
\text { Mycobacterium tuberculosis }\end{array}$ \\
\hline 3 & 0 & I & 0 & 0 & 0 & Without diagnosis \\
\hline 4 & 1 & 0 & 0 & 0 & 0 & $\begin{array}{l}\text { Pneumocystis jirovecii, enterovirus/ } \\
\text { rhinovirus }\end{array}$ \\
\hline 5 & 1 & 0 & 0 & 0 & 0 & $\begin{array}{l}\text { Pneumocystis jirovecii and Kaposi's } \\
\text { sarcoma }\end{array}$ \\
\hline 6 & 1 & 0 & 0 & 0 & 0 & Pneumocystis jirovecii \\
\hline 7 & 0 & 0 & 1 & 0 & 0 & $\begin{array}{l}\text { Pneumocystis jirovecii and } M \text {. } \\
\text { tuberculosis }\end{array}$ \\
\hline 8 & 1 & I & 0 & 0 & 0 & $\begin{array}{l}\text { Pneumocystis jirovecii, M. tuberculosis, } \\
\text { and Follicular bronchiolitis }\end{array}$ \\
\hline 9 & 0 & 0 & I & 0 & 0 & $\begin{array}{l}\text { Pneumocystis jirovecii and } \\
\text { Streptococcus gordonii }\end{array}$ \\
\hline 10 & 0 & I & 0 & 0 & 1 & M. tuberculosis \\
\hline II & 1 & I & 1 & 0 & 0 & Pneumocystis jirovecii \\
\hline 12 & 0 & 0 & I & 0 & 0 & Pneumocystis jirovecii \\
\hline 13 & 1 & I & 0 & 0 & 0 & Pneumocystis jirovecii \\
\hline 14 & I & I & 0 & 0 & 0 & $\begin{array}{l}\text { Pneumocystis jirovecii and } \\
\text { enterovirus/rhinovirus }\end{array}$ \\
\hline 15 & I & 0 & 0 & 0 & 0 & $\begin{array}{l}\text { Pneumocystis jirovecii, Escherichia coli } \\
\text { and Enterobacter cloacae }\end{array}$ \\
\hline 16 & I & 0 & 0 & 0 & 0 & Pneumocystis jirovecii \\
\hline
\end{tabular}

$>200$ cells $/ \mathrm{mL}$, and in fact, most PJP cases occur at CD4 cell counts $<100$ cells/mL, together with Mycobacterium avium complex (MAC), fungal infections, and CMV. ${ }^{13}$ The population in the study by Cattamanchi et $\mathrm{al}^{14}$ had a median $\mathrm{CD}^{+}$ T-lymphocyte count of 60 cells/mL (IQR 22-200 cells $/ \mathrm{mL}$ ), and $16 \%$ were receiving ART. TB prevalence by culture was $38 \%$, but it was positive in only $5.3 \%$ in BAL culture. The incidence of bacterial pneumonia increases starting from CD4 cell counts $<200$ cells/mL in HIV-infected patients. ${ }^{1,15}$

In our population with known history of antibiotic use prior to bronchoscopy or antiretroviral treatment, $92.8 \%$ took antibiotics and 36.6\% took ART; no statistically significant differences were found between patients with previous antibiotic use, the days with previous antibiotic, or with previous ART with the identification of etiologic agent, the presence of coinfections, or the types of etiologic agents identified. Bronchoscopic procedures are useful even after the initiation of empirical treatment if treatment duration has not exceeded 1 or 2 weeks. ${ }^{11}$

Regarding BAL yield for the diagnosis of PJP, Golden et $\mathrm{al}^{16}$ reported a $97 \%$ sensitivity, although considering their sample size, a 75\% NPV is obtained (95\% CI 30.1-95.4), and therefore, consideration must be given to their conclusions, in which they suggest the replacement of TBB by BAL. In fact, they did not directly study the role of TBB. Our results, with the sensitivities of $71.9 \%$ (95\% CI 62.8-79.6) for BAL and $89.7 \%$ (95\% CI 82.5-84.2) for TBB and $\kappa=0.583$ for both methods, support the opposite. The latter is similar to the results obtained by Broaddus et al, ${ }^{17}$ who reported an $86 \%$ yield for BAL and $87 \%$ for TBB. When both procedures were performed in the same study, the combined yield for all lung infections was $96 \%$. In contrast, Coleman et a ${ }^{18}$ reported the global sensitivities of 79 and 55\% for the diagnosis of PJP by $\mathrm{TBB}$ and $\mathrm{BAL}$, respectively.

In other series, the additive yield of TBB seems to be more important when other infections, besides PJP, are present. In this setting, Batungwanayo et $\mathrm{a}^{19}$ reported the diagnostic yields of $82 \%$ and $26 \%$, respectively, for TBB and BAL, but this reflects the wide spectrum of lung complications in African populations, where PJP is rare, but nonspecific interstitial pneumonia, TB, and Cryptococcal pneumonia were the most common diagnoses. In a retrospective analysis of 205 bronchoscopies in 182 patients, Salzman et $\mathrm{al}^{20}$ demonstrated that $26 \%$ of diagnoses were exclusively obtained with TBB, which was also the only source for the diagnosis of noninfectious 
conditions in over half of those cases (54\%). In other series of HIV-infected patients, the global yield of TBB is superior to that of BAL ( $80 \%$ vs $57.1 \%$ ), but sample sizes are small. ${ }^{21}$

Diagnoses of granulomatous inflammation were classified as benign, as no microbiological confirmation of infection was obtained. Nonetheless, in some studies, this finding is regarded as either tuberculosis or histoplasmosis, which can be overestimated. ${ }^{20}$ Miro et $\mathrm{al}^{22}$ concluded that in tuberculosis-infected patients, neither TBB nor bronchial brushings increased the diagnostic yield. In contrast to their study, our study included not only TB but also other diagnoses, which were demonstrated from TBB and BAL sampling.

The prevalence of tuberculosis in our study was higher than that previously reported in other series, even when a low sensitivity of BAL GeneXpert was observed and even though sputum production in these patients was negligible. ${ }^{23}$ This was overcome by the combination of BAL culture and BAL GeneXpert, which we did to obtain optimal samples. In contrast, TBB added some TB cases, which were not isolated by BAL. Based on this assertion, it is necessary to consider TBB samples to be routinely sent to mycobacterial culture. ${ }^{24,25}$

We found lower frequencies of CMV in BAL and of coinfections in the setting of PJP, as observed in other series. However, some of these did not look for this agent by TBB, in contrast to our study, in which diagnosis was supported with TBB findings in all six cases, with only one case showing CMV in BAL. All CMV cases were, in fact, coinfected with other pathogens (M. tuberculosis, Haemophilus influenzae, Enterococcus faecalis, Candida albicans, enterovirus, and parainfluenza type 3 virus), and five of the six cases also had PJP. ${ }^{11,26-30}$

Regarding specific diagnosis in relation to the sampling method, Shafiek et $\mathrm{al}^{31}$ found a $93 \%$ concordance of BAL with laser confocal endomicroscopy in 32 patients, but they did not compare this with TBB. Stover et $\mathrm{al}^{11}$ took as gold standard the samples obtained via bronchoscopy from BAL, TBB, cytology, BAL and/or postmortem. They found that $65 \%$ of patients had specific germ isolation. Specific figures for each diagnosis were as follows: 94\% for PJP, 67\% for CMV, $62 \%$ for MAC, and $0 \%$ for SK. For PJP, the highest yield was obtained when combining TBB and BAL. As for PJP, TBB had an $88 \%$ yield with an $85 \%$ yield for BAL, but the combination of both methods led to the best yield. Our figures also support that performance of both techniques in combination yields better results. Specifically, 54\% of the patients we studied had PJP. The differences found by using each method, BAL 51 vs TBB 91.6\%, $\kappa=0.583(P<0.001)$, show that both sampling techniques are complementary.
Cancer prevalence in our population was $2.4 \%$, and the diagnoses were demonstrated solely by TBB. It is important to remember that HIV causes a 3.5-fold increase in the risk of lung cancer and that it also occurs earlier, and its mean survival is only 3-4 weeks. ${ }^{6,13,32}$

We found alveolar hemorrhage $(\mathrm{AH})$ in $4.5 \%$ of patients, diagnosed solely by TBB. This finding occurred in association with various infections (PJP, M. tuberculosis, H. influenzae, Coccidioides immitis, MAC, and enterovirus). This was lower than that reported in the study by Vincent et al, ${ }^{33}$ who found a $32 \%$ prevalence of $\mathrm{AH}$. In their article, associations of AH with other conditions (CMV and Kaposi's sarcoma) were also observed. Regarding granulomatous inflammation and pneumonia without isolation of specific pathogens, these were suggested by the histopathological findings of TBB.

Among benign diagnoses, $\mathrm{AH}$ had a $4.5 \%$ (nine patients) prevalence in our study and the diagnosis was obtained solely by TBBs; however, since six of these patients had some other diagnosis, at the end, the specific diagnosis was considered and the $\mathrm{AH}$ diagnosis was given to only three of the nine patients. Each six patients had an infection, including PJP, M. tuberculosis, H. influenzae, C. immitis, MAC, and enterovirus. These results contrast with those reported by Vincent et $\mathrm{al}^{33}$ in their study of HIV-infected patients with pulmonary symptoms, in which the prevalence of AH was $32 \%$ but only in BAL samples, where CMV infection (OR 9.8 [95\% CI 1-91], $P=0.05$ ) and pulmonary Kaposi's sarcoma (OR 5.3 [95\% CI $1.8-16.7], P=0.003$ ) were among the main associated factors. Regarding pneumonia without isolation of the etiologic agent and granulomatous inflammation, the diagnoses were obtained by TBB through histopathological observation.

Finally, our complication figures were comparable to others, with pneumothorax in $4.5 \%$ and mild-to-moderate bleeding in $2.5 \% .^{10,11,18}$

We acknowledge the following limitations, which could have increased the diagnostic yield of each sample (BAL and TBB): lack of a larger panel for viral diagnosis via PCR and lack of specific antigen search of other microorganisms, including TB. This study has internal validity, but the external one will depend on the experience of the center in the care of patients with HIV and pneumonia and in pulmonary interventionism.

\section{Conclusion}

Our results show that the diagnosis through BAL and TBB samples is discrepant; so the simultaneous study of both samples would mean a greater diagnostic opportunity, their obtainment is safe, and they are very useful techniques to 
specifically diagnose infections and malignancies in HIVinfected patients with pneumonia.

\section{Disclosure}

The authors report no conflicts of interest in this work.

\section{References}

1. Hirschtick RE, Glassroth J, Jordan MC, et al. Bacterial pneumonia in persons infected with the human immunodeficiency virus. $N$ Engl $J$ Med. 1995;333(13):845-851.

2. Narayanswami G, Salzman S. Bronchoscopy in the human immunodeficiency virus-infected patient. Semin Respir Infect. 2003;18(2):80-86.

3. Kumar T, Epstein M, Markovskaya Y, Narasimhan M, Rosen M, Talwar A. Bronchoscopy and endobronchial disease in patients with human immunodeficiency virus infection. Indian $J$ Chest Dis Allied Sci. 2011;53(2):99-105.

4. Kanmogne GD, Kennedy RC, Grammas P. Is HIV involved in the pathogenesis of non-infectious pulmonary complications in infected patients? Curr HIV Res. 2003;1(4):385-393.

5. de Leon FC, Britt EJ. The noninfectious respiratory complications of infection with HIV. Curr Opin Pulm Med. 1995;1(3):223-233.

6. Tokman S, Huang L. Evaluation of respiratory disease. Clin Chest Med. 2013;34(2):191-204.

7. Wallace J. A reassessment of indications and diagnostic algorithms bronchoscopy in HIV disease: an update in the era of HAART. $J$ Respir Dis. 2007;28(6):244-252.

8. Kvale PA. How much bronchoscopic sampling is enough (for HIVinfected patients)? J Broncol. 1996;3(2):83-84.

9. Cazzadori A, Di Perri G, Todeschini G, et al. Transbronchial biopsy in the diagnosis of pulmonary infiltrates in immunocompromised patients. Chest. 1995;107(1):101-106.

10. Salzman SH, Bernstein LE, Villamena PC, Schneider RF, Mayo PH, Rosen MJ. Bronchoscopic lung biopsy improves the diagnostic yield of bronchoscopy in patients with known or suspected HIV infection. J Bronchol. 1996;3:88-95.

11. Stover DE, White DA, Romano PA, Gellene RA. Diagnosis of pulmonary disease in acquired immune deficiency syndrome (AIDS). Am Rev Respir Dis. 1984;130(4):659-662.

12. Kirk GD, Merlo C, O' Driscoll P, et al. HIV infection is associated with an increased risk for lung cancer, independent of smoking. Clin Infect Dis. 2007;45(1):103-110.

13. Parker MS, Leveno DM, Campbell TJ, Worrell JA, Carozza SE. AIDS-related bronchogenic carcinoma: fact or fiction? Chest. 1998;113(1):154-161.

14. Cattamanchi A, Ssewenyana I, Nabatanzi R, et al. Bronchoalveolar lavage enzyme-linked immunospot for diagnosis of smear-negative tuberculosis in HIV-infected patients. PLoS One. 2012;7(6): e39838.

15. Colangelo G, Baughman RP, Dohn MN, Frame PT. Follow-up bronchoalveolar lavage in AIDS patients with Pneumocystis carinii pneumonia: Pneumocystis carinii burden predicts early relapse. Am Rev Respir Dis. 1991;143(5 pt 1):1067-1071.

16. Golden JA, Hollander H, Stulbarg MS, Gamsu G. Bronchoalveolar lavage as the exclusive diagnostic modality for Pneumocystis carinii pneumonia. A prospective study among patients with acquired immunodeficiency syndrome. Chest. 1986;90(1):18-22.
17. Broaddus C, Dake MD, Stulbarg MS, et al. Bronchoalveolar lavage and transbronchial biopsy for the diagnosis of pulmonary infections in the acquired immunodeficiency syndrome. Ann Intern Med. 1985;102(6):747-752.

18. Coleman DL, Dodek PM, Luce JM, Golden JA, Gold WM, Murray JF. Diagnostic utility of fiberoptic bronchoscopy in patients with Pneumocystis carinii pneumonia and the acquired immune deficiency syndrome. Am Rev Respir Dis. 1983;128(5):795-799.

19. Batungwanayo J, Taelman H, Lucas S, et al. Pulmonary disease associated with the human immunodeficiency virus in Kigali, Rwanda: a fiberoptic bronchoscopy study of 111 cases of undetermined etiology. Am J Respir Crit Care Med. 1994;149(6):1591-1596.

20. Salzman SH, Schindel ML, Aranda CP, Smith RL, Lewis ML. The role of bronchoscopy in the diagnosis of pulmonary tuberculosis in patients at risk for HIV infection. Chest. 1992;102(1):143-146.

21. Williams D, Yungbluth M, Adams G, Glassroth J. The role of fiberoptic bronchoscopy in the evaluation of immunocompromised hosts with diffuse pulmonary infiltrates. Am Rev Respir Dis. 1985;131(6): 880-885.

22. Miro AM, Gibilara E, Powell S, Kamholz SL. The role of fiberoptic bronchoscopy for diagnosis of pulmonary tuberculosis in patients at risk for AIDS. Chest. 1992;101(5):1211-1214.

23. Kirk O, Gatell JM, Mocroft A, et al. Infections with Mycobacterium tuberculosis and Mycobacterium avium among HIV-infected patients after the introduction of highly active antiretroviral therapy. EuroSIDA Study Group JD. Am J Respir Crit Care Med. 2000;162(3 pt 1):865-872.

24. Agrawal M, Bajaj A, Bhatia V, Dutt S. Comparative study of GeneXpert with ZN stain and culture in samples of suspected pulmonary tuberculosis. J Clin Diagn Res. 2016;10(5):DC09-DC12.

25. Walters E, Goussard P, Bosch C, Hesseling AC, Gie RP. GeneXpert MTB/RIF on bronchoalveolar lavage samples in children with suspected complicated intrathoracic tuberculosis: a pilot study. Pediatr Pulmonol. 2014;49(11):1133-1137.

26. Tamm M, Reichenberger F, McGandy CE, et al. Diagnosis of pulmonary Kaposi's sarcoma by detection of human herpes virus 8 in bronchoalveolar lavage. Am J Respir Crit Care Med. 1998;157(2):458-463.

27. Millar AB, Patou G, Miller RF, et al. Cytomegalovirus in the lungs of patients with AIDS: respiratory pathogen or passenger? Am Rev Respir Dis. 1990;141(6):1474-1477.

28. Miles PR, Baughman RP, Linnemann CC. Cytomegalovirus in the bronchoalveolar lavage fluid of patients with AIDS. Chest. 1990;97(5): 1072-1076.

29. Tamm M, Traenkle P, Grilli B, et al. Pulmonary cytomegalovirus infection in immunocompromised patients. Chest. 2001;119(3):838-843.

30. Mann M, Shelhamer JH, Masur H, et al. Lack of clinical utility of bronchoalveolar lavage cultures for cytomegalovirus in HIV infection. Am J Respir Crit Care Med. 1997;155(5):1723-1728.

31. Shafiek H, Fiorentino F, Cosio BG, et al. Usefulness of bronchoscopic probe-based confocal laser endomicroscopy in the diagnosis of Pneumocystis jirovecii pneumonia. Respiration. 2016;92(1):40-47.

32. Hanson DL, Chu SY, Farizo KM, Ward JW. Distribution of CD4+ T lymphocytes at diagnosis of acquired immunodeficiency syndromedefining and other human immunodeficiency virus-related illnesses. The Adult and Adolescent Spectrum of HIV Disease Project Group. Arch Intern Med. 1995;155(14):1537-1542.

33. Vincent B, Flahault A, Antoine M, et al. AIDS-related alveolar hemorrhage. A Prospective Study of 273 BAL Procedures. Chest. 2001;120(4): 1078-1084. 
HIV/AIDS - Research and Palliative Care

\section{Publish your work in this journal}

HIV/AIDS - Research and Palliative Care is an international, peerreviewed open access journal focusing on advances in research in HIV its clinical progression and management options including antiviral treatment, palliative care and public healthcare policies to control viral spread. The journal is included in PubMed. The manuscript man-

\section{Dovepress}

agement system is completely online and includes a very quick and fair peer-review system, which is all easy to use. Visit http://www.dovepress. $\mathrm{com} /$ testimonials.php to read real quotes from published authors.

Submit your manuscript here: https://www.dovepress.com/hivaids---research-and-palliative-care-journal 